\title{
“COR LOCAL” E HISTÓRIA da literatura
}

Regina Zillberman

\section{Uma troca de cartas}

Em 1873, Machado de Assis (1839-1908) publicou na revista O Novo Mundo - Periódico Ilustrado do Progresso da Idade, editada em Nova York e dirigida por José Carlos Rodrigues (1844-1923), que contava com a colaboração de Joaquim de Souza Andrade, o Souzândrade (1832-1904), o ensaio que denominou "Notícia da atual literatura brasileira", também conhecido por "Instinto de nacionalidade", subtítulo da primeira parte do texto. O Novo Mundo apresentava-se como um "periódico ilustrado do progresso da política, literatura, arte e indústria”; o primeiro volume apareceu em 24 de outubro de 1870, e o último, o número 108, em dezembro de 1879.

A carta em que José Carlos Rodrigues convida Machado de Assis a participar como ensaísta está datada de 22 de setembro de 1872 e tem o seguinte teor:

New York, 22 de setembro de 1872

Ilustríssimo Senhor Machado de Assis

Dou-lhe os parabéns pelo brilhante sucesso de sua Ressurreição, que li há dias e de que hei de dizer por extenso o que penso nalgum dos próximos números de Novo Mundo.

Este jornal (que tem chegado agora ao $3^{\circ}$ ano a salvamento) precisa de um bom estudo sobre o caráter geral da literatura brasileira contemporânea, criticando suas boas ou más tendências, no aspecto literário e moral: um estudo que, sendo traduzido e publicado 
aqui em inglês, dê uma boa ideia da qualidade da fazenda literária que lá fabricamos, e da escola ou escolas do processo da fabricação. Como sabe, se não escrevo bem sobre assunto nenhum, muito menos sobre literatura; nem tenho tempo de ir agora estudá-la. Quererá o amigo escrever sobre isto? - Não posso dizer-lhe de antemão quanto lhe pagarei pelo trabalho; mas digo-lhe que desejo muito ter esse artigo e que hei de retribuir-lhe o melhor que puder, regulando-me sempre pela qualidade, náo pelo tamanho do escrito. Talvez possamos fazer algum arranjo efetivo para trabalhos deste gênero. Em todo caso estimaria ter uma ideia de quanto espera receber por seu trabalho.

No correr de 1873 vou publicar aqui traduçóes inglesas de dois romances nacionais bem conhecidos. A tradução é feita por um autor dos mais distintos que hoje escrevem no inglês.

Desejando-lhe muita saúde e as mais bênçãos cristãs, fico

De Vossa Senhoria

patrício e criado obrigado

J. C. Rodrigues. ${ }^{1}$

Machado de Assis aparentemente demorou a responder, pois sua carta, aceitando o convite, foi redigida em 25 de janeiro de 1873, sendo que, no intervalo, José Carlos Rodrigues cumpriu o prometido: a resenha dedicada a Ressurreição foi publicada em 23 de dezembro de $1872 .^{2}$ Escreve o romancista carioca:

Rio de Janeiro, 25 de janeiro de 1873

Ilustríssimo Senhor Doutor José Carlos Rodrigues,

Aperto-lhe mui agradecidamente as máos pelo seu artigo do Novo Mundo a respeito do meu romance. E não só agradeço as expressões amáveis com que me tratou, mas também os reparos que me fez. Vejo que leu o meu livro com olhos de crítico, e não hesitou em dizer o que pensa de alguns pontos, o que é para mim mais lisonjeiro que tudo. Escrevera-lhe eu mais longamente desta vez, se não fora tanta coisa que me absorveu hoje o tempo e o espírito. Entretanto não deixarei de lhe dizer desde já que as censuras relativas a algumas passagens menos recatadas são para mim sobremodo salutares. Aborreço a literatura de escândalo, e busquei evitar esse escolho no meu livro. Se alguma coisa me escapou, espero emendar-me na próxima composição.

O nosso artigo está pronto há um mês. Guardei-me para dar-lhe hoje uma última demão; mas tão complicado e cheio foi o dia para mim, que prefiro demorá-lo para o seguinte vapor. Não o faria se se tratasse de uma correspondência regular como costumo fazer para a Europa; trata-se, porém, de um trabalho que, ainda retardado um mês não perde a oportunidade. 
O nosso João de Almeida tinha-me pedido em seu nome um retrato, que lhe entrego hoje e lá irá ter às suas mãos. Não me será dado obter igualmente um retrato seu para o meu álbum dos amigos? Creia-me, como sempre,

Seu amigo, patrício admirador

Machado de Assis. ${ }^{3}$

A troca de correspondência é bastante sugestiva:

a) da parte de José Carlos Rodrigues, mostra o interesse do editor em divulgar em solo norte-americano, ou, ao menos, em Nova Yorque, onde a revista $O$ Novo Mundo era produzida, a "literatura brasileira contemporânea", seja por meio de estudos críticos, seja por meio do patrocínio de traduçóes de "romances nacionais bem conhecidos", vertidos, a se crer em suas palavras, por autores competentes e prestigiados;

b) também da parte de José Carlos Rodrigues, fica evidente o profissionalismo de sua conduta, já que o convite a Machado de Assis vem acompanhado de uma proposta de pagamento. Ainda que o editor náo esclareça qual seria o honorário, sublinha que pretende remunerar o crítico, considerando a qualidade do escrito, não sua dimensão.

c) da parte de Machado de Assis, constata-se primeiramente a reação do novel romancista - Ressurreição fora seu romance de estreia, lançado em 1872 - à leitura de José Carlos Rodrigues. Este destacou algumas virtudes identificadas na obra, mas, mesmo quando elogia, chama a atenção para suas limitaçôes, entre as quais estão as cenas tidas por ele por escandalosas. É a tais repreensóes que responde Machado de Assis, talvez por já ter passado por situação similar, quando publicou, no Jornal das Famílias, o conto "Confissóes de uma viúva moça".

d) Que Machado aceitou o convite de José Carlos Rodrigues, indica-o o segundo parágrafo da carta, em que informa estar o "nosso artigo" praticamente pronto, já que lhe faltava apenas "uma última demão". Assim, o romancista parece não ter perdido tempo, tratando logo de redigir o artigo, sem ter discutido com o editor o preço a ser cobrado por seu texto, assunto, aliás, ignorado em sua correspondência, que encerra com a promessa, por parte de Machado de Assis, de encaminhamento de um retrato seu. 


\section{2. "Nosso artigo"}

O ensaio de Machado de Assis não tardou a ser editado: "Notícia da atual literatura brasileira" apareceu em 24 de março de 1873, entre as páginas 107 e 108 . A seção dedicada à Literatura, nesse volume de O Novo Mundo, começa na página 106, que estampa, além de notícias sobre livros portugueses e ingleses, o artigo "Literatura Portuguesa”, de Castilho e Mello, ${ }^{5}$ que se estende até a metade da página 107. O ensaio brasileiro ocupa a outra metade dessa página e toda a seguinte, embora a divida com uma ilustração de uma menina à frente de um espelho, dificilmente relacionável ao teor do estudo crítico do escritor fluminense. ${ }^{6}$

"Notícia da atual literatura brasileira" não é o primeiro estudo de Machado de Assis a respeito das tendências da poesia e da prosa nacionais. Em 1858, ele já tinha publicado, em A Marmota, periódico dirigido por Paula Brito (1809-1861), o artigo "O passado, o presente e o futuro da literatura", em que avalia "o romance, o drama e a poesia" que se produziam no Brasil.7 A "Notícia da atual literatura brasileira” é uma versão expandida e mais madura do ensaio da juventude; contudo, questóes que ele discute no primeiro texto permanecem no segundo, ainda que sua perspectiva fique mais matizada no texto dos anos 70 do século XIX.

No artigo "O passado, o presente e o futuro da literatura”, "cor local”, expressão nascida na aurora do Romantismo europeu, é a palavra-chave que explica a preocupaçáo do jovem Machado com a poesia brasileira.

Assim, após bradar contra "o peso das medidas despóticas de um governo absoluto e bárbaro", características do "terror de uma época colonial”, ele examina as consequências do período sobre os autores nascidos no Brasil. Seu alvo principal é Tomás Antônio Gonzaga (1744-1810), condenado por carecer de "cor local" em suas liras. Adepto consciente ou involuntário da observação que Almeida Garrett (1799-1854) expóe no "Bosquejo da história da poesia e língua portuguesa”, de 1826, Machado investe contra os versos do Dirceu de Marília:

A poesia de então tinha um caráter essencialmente europeu. Gonzaga, um dos mais líricos poetas da língua portuguesa, pintava cenas da Arcádia, na frase de Garrett, em vez de dar uma cor local às suas liras, em vez de dar-lhes um cunho puramente nacional. Daqui uma grande perda: a literatura escravizava-se em vez de criar um estilo seu, de modo a poder mais tarde influir no equilíbrio literário da América.

Com efeito, é fácil reconhecer o eco das palavras do poeta português, que, em 1826, sentenciara: 
Gonzaga, mais conhecido pelo nome pastoril de Dirceu, e pela sua Marília, cuja beleza e amores tấo célebres fez naquelas nomeadas liras. Tenho para mim que há dessas liras algumas de perfeita e incomparável beleza: em geral a Marília de Dirceu é um dos livros a quem o público fez imediata a boa justiça. Se houvesse por minha parte de lhe fazer alguma censura, só me queixaria, não do que fez, mas do que deixou de fazer. Explico-me: quisera eu que em vez de nos debuxar no Brasil cenas da Arcádia, quadros inteiramente europeus, pintasse os seus painéis com as cores do país onde os situou. Oh! e quanto não perdeu a poesia nesse fatal erro! se essa amável, se essa ingênua Marília fosse, como a Virgínia de Saint-Pierre, sentar-se à sombra das palmeiras, e enquanto lhe revoavam em torno o cardeal soberbo com a púrpura dos reis, o sabiá terno e melodioso, - que saltasse pelos montes espessos a cotia fugaz como a lebre da Europa, ou grave passeasse pela orla da ribeira o tatu escamoso, - ela se entretivesse em tecer para o seu amigo e seu cantor uma grinalda não de rosas, não de jasmins, porém dos roxos martírios, das alvas flores dos vermelhos bagos do lustroso cafezeiro; que pintura, se a desenhara com sua natural graça o ingênuo pincel de Gonzaga! ${ }^{8}$

Quase quinze anos depois, Machado ainda não se libertou inteiramente do conceito formulado na juventude. Porém, em 1873, sua situação mudou: é um crítico consagrado e um dramaturgo com obra publicada, além de pertencer ao seleto grupo do Conservatório Dramático, podendo desempenhar a funçáo de censor de peças teatrais. Outrossim, o já então renomado editor Baptiste Louis Garnier (1823-1893) patrocinara a publicação de seus Contos fluminenses e dos poemas de Crisálidas, em 1864, e Falenas, em 1870, além do romance Ressurreição, em 1872.

A posição conquistada no sistema literário da Corte carioca no começo dos anos 70, do século XIX, somada ao fato de que Machado dirigia-se ao público de um jornal impresso e distribuído nos Estados Unidos, deve ter modulado seu discurso. Contudo, o critério relativo à presença ou ausência da "cor local” permanece o mediador entre o escritor e as obras literárias nacionais.

A expressão "cor local" aparece, pelo menos, sete vezes no texto. O parágrafo de abertura introduz seu pensamento e a presença do conceito em questão:

Quem examina a atual literatura brasileira reconhece-lhe logo, como primeiro traço, certo instinto de nacionalidade. Poesia, romance, todas as formas literárias do pensamento buscam vestir-se com as cores do país, e não há negar que semelhante preocupação é sintoma de vitalidade e abono de futuro. As tradiçōes de Gonçalves Dias, Porto Alegre e Magalhães são assim continuadas pela geração já feita e pela que ainda agora madruga, como aqueles continuaram as de José Basílio da Gama e Santa Rita Durão. Escusado é dizer a vantagem deste universal acordo. Interrogando a vida brasileira e a natureza americana, prosadores e poetas acharão ali farto manancial de inspiração e irão dando 
fisionomia própria ao pensamento nacional. Esta outra independência não tem Sete de Setembro nem campo de Ipiranga; não se fará num dia, mas pausadamente, para sair mais duradoura; não será obra de uma geração nem duas; muitas trabalharão para ela até perfazê-la de todo. ${ }^{9}$

Os parágrafos subsequentes seguem na mesma direção, mas, aos poucos, o ensaísta introduz suas manifestações de desconforto perante a ideia de "vestir-se com as cores do país" ser a única opção para quem desejar produzir literatura autenticamente nacional:

Sente-se aquele instinto até nas manifestaçôes da opinião, aliás mal formada ainda, restrita em extremo, pouco solícita, e ainda menos apaixonada nestas questôes de poesia e literatura. Há nela um instinto que leva a aplaudir principalmente as obras que trazem os toques nacionais. A juventude literária, sobretudo, faz deste ponto uma questão de legítimo amor-próprio. Nem toda ela terá meditado os poemas de Uruguai e Caramuru com aquela atenção que tais obras estão pedindo; mas os nomes de Basílio da Gama e Durão são citados e amados, como precursores da poesia brasileira. A razão é que eles buscaram em roda de si os elementos de uma poesia nova, e deram os primeiros traços de nossa fisionomia literária, enquanto que outros, Gonzaga por exemplo, respirando aliás os ares da pátria, não souberam desligar-se das faixas da Arcádia nem dos preceitos do tempo. Admira-se-lhes o talento, mas não se lhes perdoa o cajado e a pastora, e nisto há mais erro que acerto.

Dado que as condiçôes deste escrito o permitissem, não tomaria eu sobre mim a defesa do mau gosto dos poetas arcádicos nem o fatal estrago que essa escola produziu nas literaturas portuguesa e brasileira. Náo me parece, todavia, justa a censura aos nossos poetas coloniais, iscados daquele mal; nem igualmente justa a de não haverem trabalhado para a independência literária, quando a independência política jazia ainda no ventre do futuro, e mais que tudo quando entre a metrópole e a colônia criara a história a homogeneidade das tradiçóes, dos costumes e da educação. As mesmas obras de Basílio da Gama e Durão quiseram antes ostentar certa cor local do que tornar independente a literatura brasileira, literatura que não existe ainda, que mal poderá ir alvorecendo agora.

É ao examinar o romance de seu tempo que Machado recorre, pela terceira vez, à noção de cor local. Reconhece a persistência da busca, pelos autores, por retratar a vida brasileira, admitindo que esse projeto realiza-se melhor quando a açáo reflete a vida interiorana, menos afeita à influência dos costumes europeus:

Aqui o romance, como tive ocasião de dizer, busca sempre a cor local. A substância, não menos que os acessórios, reproduzem geralmente a vida brasileira em seus diferentes aspectos e situaçóes. Naturalmente os costumes do interior são os que conservam melhor 
a tradição nacional; os da capital do país, e em parte, os de algumas cidades, muito mais chegados à influência europeia, trazem já uma feição mista e ademanes diferentes.

Ao abordar a poesia, o ensaísta verifica mais uma vez a presença da cor local, citando-a então pela quarta vez. Nessa etapa do ensaio, evidencia-se que o critério localista não entusiasma o crítico, que aproveita para destacar os defeitos dos poemas de seus contemporâneos:

Não faltam à nossa atual poesia fogo nem estro. Os versos publicados são geralmente ardentes e trazem o cunho da inspiração. Náo insisto na cor local; como acima disse, todas as formas a revelam com mais ou menos brilhante resultado, bastando-me citar neste caso as outras duas recentes obras, as Miniaturas de Gonçalves Crespo e os Quadros de J. Serra, versos estremados dos defeitos que vou assinalar. Acrescentarei que também não falta à poesia atual o sentimento da harmonia exterior. Que precisa ela então? Em que peca a geração presente? Falta-lhe um pouco mais de correção e gosto, peca na intrepidez às vezes da expressão, na impropriedade das imagens, na obscuridade do pensamento. A imaginação, que há deveras, não raro desvaira e se perde, chegando à obscuridade, à hipérbole, quando apenas buscava a novidade e a grandeza.

A rejeição do critério intensifica-se em parágrafo subsequente, quando Machado investe energicamente contra o conceito com que iniciara seu exame da "atual literatura brasileira"

Há também uma parte da poesia que, justamente preocupada com a cor local, cai muitas vezes numa funesta ilusão. Um poeta não é nacional só porque insere nos seus versos muitos nomes de flores ou aves do país, o que pode dar uma nacionalidade de vocabulário e nada mais. Aprecia-se a cor local, mas é preciso que a imaginação lhe dê os seus toques, e que estes sejam naturais, não de acarreto.

Não surpreende que, ao encerrar a "notícia”, o ensaísta retome, pela última vez, o conceito de "cor local", para citá-lo entre os "defeitos e as excelências" da literatura brasileira de seu tempo:

Aqui termino esta notícia. Viva imaginação, delicadeza e força de sentimentos, graças de estilo, dotes de observação e análise, ausência às vezes de gosto, carências às vezes de reflexão e pausa, língua nem sempre pura, nem sempre copiosa, muita cor local, eis aqui por alto os defeitos e as excelências da atual literatura brasileira, que há dado bastante e tem certíssimo futuro.

Ao longo do ensaio, como se observou, Machado mostra seu incômodo diante da noção de "cor local", alçada a critério de valor. Note-se que, no texto redigido quinze anos 
antes, ele abraçara a ideia, encampando também a denúncia de Garrett relativamente à possível inautenticidade dos versos de Gonzaga. Passado o tempo, e mudadas as vontades, o ficcionista pode descartar o princípio adotado, recusando ao mesmo tempo a perspectiva do autor do "Bosquejo da história da poesia e língua portuguesa". Contudo, admirador do poeta português, admiração que se estende até o final de sua vida, Machado evita citar seu nome, provavelmente para não ter de confessar que discordava do mestre.

Se Machado, de um lado, contraria a afirmação de Almeida Garrett, formulada aproximadamente cinquenta anos antes, de outro, ele não contesta frases oriundas de seu arroubo juvenil. Assim, a observação, na "Notícia" de que "esta outra independência não tem Sete de Setembro nem campo de Ipiranga; não se fará num dia, mas pausadamente, para sair mais duradoura; não será obra de uma geração nem duas; muitas trabalharão para ela até perfazê-la de todo" pode ser entendida como a convicção do Machado maduro, ecoando o entusiasmo do Machado jovem, em "O passado, o presente e o futuro da literatura”, onde ele afirma peremptoriamente:

Uma revolução literária e política fazia-se necessária. O país não podia continuar a viver debaixo daquela dupla escravidão que o podia aniquilar.

A aurora de 7 de setembro de 1822, foi uma aurora de uma nova era. O grito do Ipiranga foi o - Eureka - soltado pelos lábios daqueles que verdadeiramente se interessavam pela sorte do Brasil, cuja felicidade e bem-estar procuravam.

O país emancipou-se. A Europa contemplou de longe esta regeneraçâo política, esta transição súbita da servidão para a liberdade, operada pela vontade de um príncipe e de meia dúzia de homens eminentemente patriotas. Foi um a honrosa conquista que nos deve encher de glória e de orgulho; e é mais que tudo uma eloquente resposta às interrogaçóes pedantescas de meia dúzia de céticos da época: o que somos nós?

Havia, digamos de passagem, no procedimento do fundador do império um sacrifício heróico, admirável, e pasmoso. Dois tronos se erguiam diante dele: um, cheio de tradiçốes e de glórias; o outro, apenas saído das mãos do povo, não tinha passado, e fortificava-se só com uma esperança no futuro! Escolher o primeiro, era um duplo dever, como patriota e como príncipe. Aquela cabeça inteligente devia dar o seu quinhão de glória ao trono de D. Manuel e de D. João II. Pois bem! ele escolheu o segundo, com o qual nada ganhava, e ao qual ia dar muito. Há poucos sacrifícios como este.

Mas após o Fiat político, devia vir o Fiat literário, a emancipação do mundo intelectual, vacilante sob a açáo influente de uma literatura ultramarina. Mas como? é mais fácil regenerar uma nação, que uma literatura. Para esta não há gritos de Ipiranga; as modificaçôes operam-se vagarosamente; e não se chega em um só momento a um resultado. 
Pode-se supor que, para redigir a "Notícia", Machado tenha relido, revisto e ampliado seu texto de 1858, ponto de partida para dar conta da encomenda de José Carlos Rodrigues. O artigo original, por sua vez, foi antecipado pela leitura do "Bosquejo da história da poesia e língua portuguesa”, de Almeida Garrett, situação que não surpreende, pois aquele estudo recebeu, entre 1840 e 1860, pelo menos duas ediçóes no Brasil: a Biblioteca Juvenil, fragmentos morais, históricos, literários, políticos e dogmáticos, extraídos de diversos autores e oferecidos à mocidade brasileira, editada em 1844 por Antônio Maria Barker (conforme Henrique de Campos Ferreira Lima, ${ }^{10}$ professor de primeiras letras e membro efetivo da Sociedade Literária do Rio de Janeiro), teria reproduzido quase integralmente o "Bosquejo da história da poesia e língua portuguesa". Por sua vez, Alexandre José de Melo Moraes (1816-1882), intelectual atuante no Rio de Janeiro da década de 1850, transcreveu inteiramente o texto nos Elementos de literatura, obra de 1856, intitulando-o, porém, História abreviada da literatura portuguesa e brasileira ${ }^{11}$ Essas obras, adotadas pelo Colégio Pedro II e que logo receberam novas ediçôes (a de Barker, em 1856, atinge a quarta edição, e a de Melo Moraes é reproduzida em 1858), colaboraram para a difusão das ideias de seu autor e talvez tenham constituído o canal que as conduziu até o jovem Machado de Assis.

O "Bosquejo da história da poesia e língua portuguesa" indica como a noção de "cor local", que afiança a nacionalidade da literatura, no caso, a brasileira, nasce no bojo das histórias da literatura. O texto assinado por Almeida Garrett aparece na condição de introdução à coletânea de poesia intulada Parnaso lusitano, posição que talvez o afaste das histórias da literatura, considerado o modo como já no começo do século XIX esse gênero era praticado, bastante similar àquele que ainda hoje conhecemos. Contudo, critério idêntico tem lugar central nos Résumé de l'histoire littéraire du Portugal, suivi du Résumé de l'histoire littéraire du Brésil, que Ferdinand Denis (1798-1890) publica em 1826, em Paris, o mesmo ano e a mesma cidade em que aparece o estudo do poeta português.

Nascido em 1798, Ferdinand Denis é apenas um ano mais velho que Garrett, de 1799; mas, em 1826, o historiador francês já tinha produzido alguns textos seminais, tais como: Le Brésil, ou Histoire, moeurs, usages et coutumes des habitants de ce royame, de 1821-1822, escrito em parceria com H. Taunay (1793-1864); e, sobretudo, Scènes de la nature sous les tropiques et de leur influence sur la poésie, de 1824, obra onde se encontra a novela biográfica "Camöens et Jozé Indio", além de incluir dois relatos, um indianista, "Os maxacalis", ${ }^{12}$ e outro, abolicionista, "Palmares". ${ }^{13}$ De 1825 data Résumé de l'histoire du Brésil et de la Guyane, que alcançou duas ediçōes naquele ano. Esse livro foi traduzido no Brasil por Henrique Luís de Niemeyer Bellegarde (1802-1839) e, conforme Joaquim Norberto (1820-1891), "adotado por circular do governo às câmaras municipais 
do império para leitura das escolas primárias". ${ }^{14} \mathrm{O}$ Résumé de l'histoire littéraire du Portugal, suivi du Résumé de l'histoire littéraire du Brésil contém duas partes, dedicada a primeira e mais longa à literatura de Portugal; a segunda, bem menos extensa, abriga as obras atribuídas a autores nascidos no Brasil, entendidos enquanto um universo distinto, mesmo quando inclui poetas que viveram a maior parte de sua vida no Velho Continente, como Santa Rita Durão (1722-1784), responsável pelo Caramuru. Denis não utiliza o crivo da "cor local" apenas para observar a literatura dos brasileiros; mesmo quando aborda os portugueses, Denis os faz passar pelo filtro que, anos depois, motiva o embaraço de Machado de Assis.

O exame da obra de Luís de Camóes (1524?-1580) exemplifica o procedimento de Ferdinand Denis. Sua poesia é louvada, porque nela "domina notável cor local e grande observação da natureza" ${ }^{15}$ Ao analisar Os Lusiadas, chama a atenção para o modo como Camóes aborda os povos estrangeiros, extraindo deles a cor local para conferir verossimilhança a seus versos:

Desde essa primeira descrição da atitude e dos usos de um povo estrangeiro, Camóes mostra-nos que exatidáo, que cor local ele deve conservar nas numerosas pinturas das regiôes distantes. (p. 81)

Também quando tece consideraçóes sobre o teatro de Antônio Ferreira (15281569), o critério relativo à cor local serve-lhe de parâmetro para medir a qualidade da dramaturgia do século XVI português:

Como Inês de Castro, $O$ cioso, o ciumento, peca pela ação; mas o estilo é variado, frequentemente cômico, e seguidamente pleno da cor local que não encontramos entre um imitador dos antigos. (p. 166)

Mais adiante, é a poesia de Fernão Álvares do Oriente (c. 1540-c. 1600), em Lusitânia transformada, que motiva a observação de Denis relativamente à presença da "cor oriental que se encontra tão frequentemente na literatura portuguesa". (p. 204)

Nos exemplos citados, Ferdinand Denis refere-se a autores do século XVI, que se expressaram em verso e em prosa, no caso da dramaturgia de Antônio Ferreira. Portugal é, no período, uma das principais potências europeias, depois de ter constituído uma das primeiras regióes geográficas a lutar por sua autonomia e a se configurar como Estado independente, o que lhe assegurou a incorporação antecipada de um sentimento de nação, de que Os Lusiadas é provavelmente a primeira expressão.

Ferdinand Denis pôde reconhecer o sentido da nacionalidade na bem-resolvida literatura portuguesa do século XVI. Porém, a expressão nada significava para os homens daquela época, que, como Camóes, preferiam entender os feitos narrados como o 
triunfo da civilização cristá sobre o paganismo e a — segundo eles — barbárie oriental. Essa circunstância não impediu que Denis transportasse uma perspectiva de seu tempo - a cor local enquanto sinônimo de manifestação de identidade e singularidade para a época dos vates renascentistas.

Como se vê, nem a literatura portuguesa estava em fase de afirmação, nem ela apresentava teor nativista e autóctone, ao contrário da literatura brasileira produzida no século XIX e interpretada por Machado de Assis. Contudo, o historiador francês só consegue examiná-la com os valores da cor local e da expressão do nacional. A partir desse ponto, esses critérios transplantam-se para as literaturas emergentes e acabam por se ajustar a elas até com mais facilidade. Apesar dessa circunstância, não se pode afirmar que essas literaturas emergentes tenham-nos suscitado.

Por consequência desse duplo transplante - do pensamento historiográfico do século XIX para as expressóes literárias precedentes; da valorização da cor local e da expressão autenticamente nacional, própria a toda arte da palavra, conforme aquele pensamento, para a situação específica da literatura escrita e veiculada no Brasil - Machado de Assis, em dois momentos de sua vida de crítico, pôde utilizá-los, primeiramente na posição de seu advogado, depois, na condição de seu antagonista. O escritor carioca provavelmente não leu o Résumé de l'histoire littéraire du Portugal, suivi du Résumé de l'histoire littéraire du Brésil, de Ferdinand Denis, que não foi traduzido para a língua portuguesa, ao contrário de seu bem sucedido livro de história do Brasil; mas não ficou imune ao conceito originário da história da literatura que se convertia em pedra-detoque da crítica literária e da historiografia da literatura portuguesa.

A história da literatura dava as cartas, cuja banca era ocupada por Ferdinand Denis, ainda que seu livro circulasse exclusivamente em francês.

\section{NOTAS}

\section{$\operatorname{son} 2$}

1 ASSIS, Machado de. Correspondência de Machado de Assis. Coordenação e orientação Sergio Paulo Rouanet. Rio de Janeiro: ABL, 2009. Tomo II, p. 79-80.

2 A resenha está reproduzida em [RODRIGUES, José Carlos]. Um romance fluminense. In: MACHADO, Ubiratan (Org.). Machado de Assis - roteiro da consagraçáo (crítica em vida do autor). Rio de Janeiro: EDUERJ, 2003. p. 89-92.

3 ASSIS, Machado de. Correspondência de Machado de Assis. p. 82-83.

4 Cf. ZILBERMAN, Regina. Leitora de folhetim em um conto do Jornal das Famílias. In: __. Brás Cubas autor Machado de Assis leitor. Ponta Grossa: Ed. da UEPG, 2012.

5 Augusto Ernesto de Castilho e Mello, de Portugal, formou-se em Matemática pela Universidade de Coimbra. Foi cavaleiro da Ordem de Nossa Senhora da Conceição de Vila Viçosa e Secretário Geral 
do distrito de Bragança. Cf. BARROSO DA FONTE (Coord.). Dicionário dos mais ilustres Trasmontanos e Alto Durienses. Guimarães: Editora Cidade Berço, s. d.

6 No mesmo ano, Machado de Assis publicou "Notícia da atual literatura brasileira" no imprensa liberal, o que permitiu sua divulgaçáo por intermédio do jornal $A$ Reforma, lançado em várias capitais provinciais. V. BERGAMINI, Atilio. "Instinto de nacionalidade" na imprensa liberal. Machado de Assis em linha. Rio de Janeiro, v. 6, n. 12, p. 15-31. Dez. 2013.

7 ASSIS, Machado. O passado, o presente e o futuro da literatura. In: volumes. Rio de Janeiro: Nova Aguilar, 2008. V. 3. p. 1002-1006.

8 Garrett, João Batista Leitão de Almeida. Bosquejo da história da poesia e língua portuguesa. In: ZILBERMAN, Regina; MOREIRA, Maria Eunice. O berço do cânone. Porto Alegre: Mercado Aberto, 1998. p. 57-58. Originalmente publicado em: Parnaso Lusitano. Paris: J. P. Aillaud, 1826. V. I.

9 ASSIS, Machado de. Literatura brasileira — instinto de nacionalidade. In: Crítica Literária. São Paulo: Mérito, 1959. p. 129-149.

10 Cf. Lima, Henrique de Campos Ferreira. Garrett e o Brasil. Revista de Lingua Portuguesa, p. 119.

11 Cf. Moraes, Alexandre José de Melo. Elementos de literatura. Primeira parte, contendo a arte poética, a mitologia, a idiologia (sic), a gramática, a lógica, e a retórica. Rio de Janeiro: Tipografia Americana, 1856. p. 153-177.

12 Essa novela tem uma versão publicada no Brasil: Denis, Ferdinand. Os maxacalis. Edição crítica com introdução, notas e apêndice de Jean-Paul Bruyas. Trad. de Maria Cecília de Moraes Pinto. São Paulo: Secretaria da Cultura, Ciência e Tecnologia; Conselho Estadual de Artes e Ciências Humanas, 1979.

13 Essa novela tem uma versão publicada no Brasil: DENIS, Ferdinand. Palmares Trad. de Maria Helena Rounet. Cadernos do Centro de Pesquisas Literárias da PUCRS. Porto Alegre: EDIPUCRS, 1997.

14 NORBERTO, Joaquim. Atas das sessóes de 1890. Revista Trimensal do Instituto Histórico e Geográfico Brasileiro. Rio de Janeiro, n. 53, p. 474 - 477. 1890.

15 DENIS, Ferdinand. Resumé de l'histoire littéraire du Portugal, suivi du Résumé de l'histoire littéraire du Brésil. Paris: Lecointe et Durey, Libraires, 1826. p. 137. Tradução nossa.

\section{Resumo}

A hipótese de que a identidade nacional repousa na literatura remonta ao Romantismo, que formulou a noção de cor local. O termo, resultante das aproximaçóes entre literatura e pintura, adequou-se às literaturas de língua portuguesa, que encontraram em Ferdinand Denis um de seus primeiros historiadores. Ao redigir o Résumé de l'histoire littéraire du Portugal, suivi du Résumé de l'histoire littéraire du Brésil, em 1826, Denis busca as tintas que garantem a nacionalidade da literatura. Ao fazê-lo, estabelece um paradigma para a história da literatura que se mantém vivo contemporaneamente.

Palavras-chave: cor local; identidade nacional; história da literatura.

\section{Abstract}

The hypothesis that national identity rests on literature dates back to Romanticism, which formulated the notion of "local color". The term, resulting from the similarities between literature 
and painting, suited to those literatures in Portuguese language, being Ferdinand Denis one of its earliest historians. In writing the Résumé de l'bistoire littéraire du Portugal, suivi du Résumé de l'bistoire littéraire $d u$ Brésil, in 1826, Denis search es the colors that ensure the nationality of the literature. By doing so, he provides a paradigm for the history of literature that remains contemporary nowadays.

Keywords: local color; national identity; history of literature.

Légua $8 x$ meia

ZILBERMAN, Regina "Cor local” e história da literatura. Légua

Regina Zilberman possui graduação em Letras pela Universidade Federal do Rio Grande do Sul (1970), doutorado em Romanística - Universidade de Heidelberg (Ruprecht-Karls) (1976), e pós-doutorado no University College (Inglaterra) (1980-1981) e Brown University (EUA) (1986-1987). Atualmente é professora adjunta do Instituto de Letras, da UFRGS. 